\title{
PSYCHOLOGICAL FEATURES OF REPRESENTATIVES OF THE CHECHEN YOUTH PROFESSING ISLAM AND EXPERIENCING MYTHOLOGICAL FEARS
}

\author{
Dr. Grimsoltanova Razet Elbrusovna, candidate of psychology and a research worker of the \\ Federal State-financed Establishment of Science Complex research institute named after Kh. I. Ibragimov of the \\ Russian Academy of Sciences \\ E-mail: Razet Grims@mail.ru \\ Dr. Batygov Ziyaudin Osmanovitch, pro-rector on the scientific work, Federal State Budget Educational Institution \\ of The Higher Professional Education «Ingush State University». \\ E-mail: bat-zo@yandex.ru
}

Received: March, 30.2015.

Accepted: May, 05.2015.

Original Article

UDK 159.942.5.072-053.6(470.66)

\begin{abstract}
The article described the study of the relevance of the role and place of religious contents among young people in the postconflict areas of the South of Russia, the rate of experiences of mythological fear had been explored with the help of the survey, as well as individual psychological characteristics of subjects had been studied by methods of Eysenck, Schmieschek, J. Rotter and Taylor. Those representatives of the surveyed youth sample experiencing a high level of mythological fear could fall into the danger zone of initiation in the group of non-traditional religious sects, as well as come under extremists' influence, since manip-ulation of consciousness and human behavior, depending on individual psychological characteristics and by using of mythological content, such as fear of possession by jinni, is most effective. The study was attended by representatives of Islam at the age of 19-21, divided by gender: 100 young men and 100 girls. The study was aimed at identifying indi-vidual personality characteristics of temperament, character accentuations, locus of control, the level of personal anxiety and the results of a content analysis of the survey done by the author of the article were identified in accordance with five scales. Results of the study revealed that about $80 \%$ of subjects experiencing a high level of mythological fears had the same peculiar correlation indices. In connection with the results of research, we had worked out and suggested a complex of psycho-pedagogical support consisting of four modules for the purpose of education, preventive and corrective activities with young people

Corresponding Author

Dr. Grimsoltanova Razet Elbrusovna, candidate of psychology and a research worker of the Federal Statefinanced Establishment of Science Complex research institute named after Kh. I. Ibragimov of the Russian Academy of Sciences

E-mail: $\underline{\text { Razet Grims@mail.ru }}$
\end{abstract}

experiencing a high level of mythological fear (fear of possession by jinni).

Keywords: Religion, Mythological fear, Possession by jinni, Adolescence, Psychological characteristics, Post-conflict region.

\section{INTRODUCTION}

Speaking of myth as a phenomenon almost inextricably linked with religion, it should be noted that despite being similar in a deeply personal sphere, religion and myth still have a difference. In religion, people are looking for faith, salvation, justification, consolation, as it expresses the inner, spiritual side. In the myth, the man also has the possibility to express himself, to speak, to have his own history. Myth suggests a person an opportunity to express his personality.

The world of myth has harmony, strict order and is not subject to the logic of practical experience. Myth exists as a kind of hypothesis, impromptu judgment of reality. And, most importantly, creating such a reality man takes it as the only reliable. However, it's necessary to remember that excessive mythologizing of a person can actualize existential fears related to certain religious threats. Thus, excessive anxiety over certain mythological settings related to, for example, superstition, signs, witchcraft, belief inspirits negative impact, can function as a destructive transformation and deformation of the person, as on the stage of excessive mythologizing, religiousness is beginning to be excessive. For the present 
study, of particular interest is the influence of religion and anxiety over mythological fears on individual psychological characteristics of modern representative of Islam in the period of youth, especially in post-conflict areas, where the problems of religious belief and religious myths, can be transformed by the fact that society has survived a collective stress or moment in its development. Currently, psychology virtually has no research on identifying mythological fears (particularly the phenomenon of possession by jinni) among youth and who is most vulnerable to excess anxiety over mythological content. Evidence that a sufficiently large number of Chechen youth is at high level of experiencing mythological fears has become the impetus for this study.

\section{MATERIALS AND METHODS}

The study involved subjects in the amount of 200 people: 100 young men and 100 girls of the same age category. For quantitative and qualitative research results, we have developed a diagnostic system including the questionnaire we have worked out and dedicated to the study of the sphere of experiencing mythological fears among representatives of Islam in adolescence consisting of five scales (Grimsoltanova R. E, 2014a) and 4 methods: Eysenck Personality Inventory, J. Rotter's test on the locus of control, Schmieschek character accentuations questionnaire, analysis of the anxiety level according to Taylor (Grimsoltanova R. E, 2014b). To obtain the percentage data comparing the gender groups and subgroups divided into those who are experiencing high and medium level of anxiety over mythological fears, we used standard programs STATISTIKA 6.0, MATHLAB 7.0. For correlation study, we used Spearman rank correlation method, adjusted for the same ranks.

\section{RESULTS}

The pilot study revealed the following results: In the course of the survey we obtained data on 5 scales of the questionnaire. Results of the study on the first scale revealed the average age of the subjects equal to 20 -years, and indicated that $100 \%$ of participants identify themselves as members of a religious group, professing the religion of Islam, also $100 \%$ of the subjects believe their family to be religious. The obtained data are the result of study of the survey samples of both gender groups. The second scale study aimed at identifying the level of awareness of man about interpretation of certain religious concepts associated with the manifestation of good and evil, revealed results with no significant difference between gender groups. In both groups, on this scale, the results obtained were from $60 \%$ to $98 \%$ with a positive answer to the question about belief in evil spirits, devils, angels and jinni. In the existence of evil spirits from a religious point of view, believe $82 \%$ of the subjects of young men and $87 \%$ of the subjects of girls. Belief in the existence of the devil among the subjects of both groups is almost equal - about $80 \%$.Regarding beliefs in existence of angels, the subjects give $98 \%$ of affirmative answers in both groups. Also, subjects in both groups almost equally, from $96 \%$ to $98 \%$, believe in the existence of the jinni. The third scale survey questions are related to identification of the level of semantic units associated with fatality and catastrophization in understanding the impact of religion on the control of the human psyche. The question related to the real ability of each person to move into the body of the jinni the subjects of both groups gave positive answers amounting $82 \%$ to $87 \%$. To a similar question but related directly to their personalities, subjects gave far less positive answers, $51 \%$ - in the men's group, $42 \%$.in the women's. However, when asked the same question but with more precise religious aspect: "Do you admit the possibility of your exposure to, and the influence of supernatural forces on your from the religious point of view?", we received a higher percentage of positive answers, equal to $58 \%$, in the women's group, The question related to the statement of experiencing individually symptoms of possession by other-worldly forces, even smaller percentage of positive answers from $19 \%$ to $21 \%$ were received from the subjects in both groups The final question of the scale, is a question related to the possibility for a believer to be possessed by jinni, to which subjects responded positively $66 \%$ in the men's group, $72 \%$.in the women's group. The fourth scale of the questionnaire designed to identify to what extent people are really faced with problems of psychological threats from religious phenomena and to what extent these problems affect their real life world, showed the following results presented in Figure 1. 
Figure 1. Results of responses to the questionnaire on the fourth scale

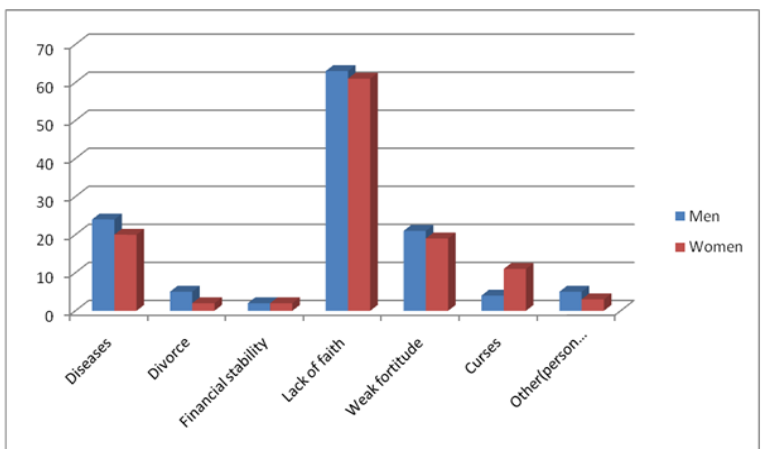

In the matter of who is at fault in the cause of human possession by jinni, of the options of answers presented, only $10 \%$ of the subjects of women's groups believe the reason of possession is the curse; $20 \%$ of men and $18 \%$ of women believe that it is the weakness of fortitude; $21 \%$ of men and $19 \%$ of women believe that the reason is in diseases, and the highest rate of $64 \%$ among men and $62 \%$ among women believe that the main reason for a man's possession by jinni is the lack of faith.

Finally, the fifth and the last scale of the questionnaire presents the question of the extent to which a person is aware of the fact that the society offers specific psychological mechanisms to protect themselves from psychological threats from demonic influence through religion.

To the question "Should we be afraid of the jinni" the subjects gave affirmative answers $-24 \%$ in the group of men, $45 \%$.-in the group of women.

To the question: "Who can liberate man from the devil's (jinni) possession" out of the 5 proposed options of answers, $56 \%$ male and $54 \%$ of the women's sample chose "religious representative."

As a result of the survey to identify the presence and degree of mythological fears among representatives of Islam in adolescence in the postconflict territory of Southern Russia, and analysis of the data obtained we had received the results corresponding to the following parameters: $81 \%$ out of $99 \%$, of young men experience a high level of mythological fears; $18 \%$ of young men experience average mythological fears; $79 \%$ of girls out of 100 , experience a high level of mythological fears; $21 \%$ of girls experience average mythological fears. In processing the results of Schmieschek Personality Inventory respondents with different levels of mythological fears experience showed accentuation differences in subgroups divided into those experiencing high and medium level of mythological fears, symbolically divided into groups M1, M2, G1, G2 (Figure 2).

Figure 2. High level of mythological fears experience - "Believe." The average level of mythological fears experience - "Do not believe / Doubt."

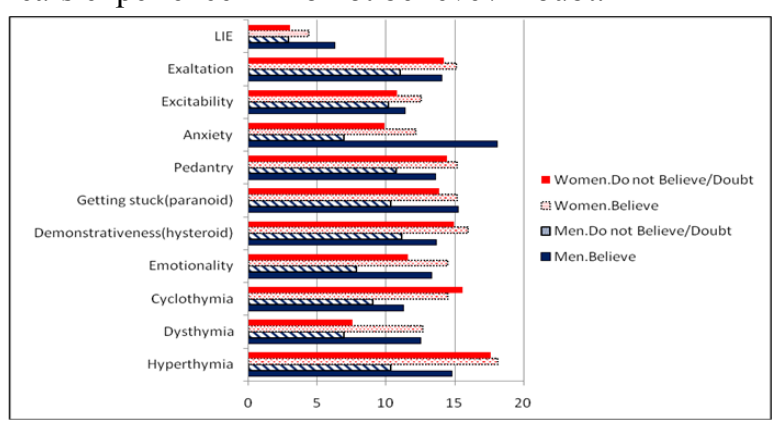

The diagram showed that the survey sample in the men's group showed accentuated degree among young men in groupsM1 and M2, on the following parameters: hyperthymia in group M1was more expressed than in the group M2; emotionality, demonstrativeness (hysteroid), getting stuck (paranoid), pedantry and anxiety were also prevalent in the group with high-level index of mythological fears experience.

In the women's survey sample, the severity of accentuation in groups $\mathrm{R} 1$ and $\mathrm{R} 2$, except for the accentuation of exaltation, was distributed with the same prevalence as in the men's group of hyperthymia; emotionality; demostrativeness (hysteroid), getting stuck (paranoid) and pedantry in the group G1.

The test data processed according to Taylor to identify the level of personal anxiety of respondents with different levels of mythological fears experience, showed that in the men's sample group anxiety among young men experiencing a high level of mythological fears was $2 \%$ higher than in the second group. Also in the women's sample group indicator of the level of anxiety among girls experiencing a high degree of mythological fears was higher (with a difference of $2 \%$ ) than in the second group of girls.

Data obtained from the analysis of the test questionnaire to identify the locus of control had revealed results that showed that in the sample group of young men experiencing a high level of mythological fears internality index was lower than that of young men of the second group (M2). In the sample group G1, among women experiencing a high level of mythological fears internality index was also lower than in girls of group G2. 


\section{DISCUSSIONS}

Initially, we planned to divide the entire survey sample into three groups of those who believe, doubt and do not believe in the phenomenon of human possession by jinni.

However, the data obtained by the content analysis of the survey allowed us to identify out of two gender groups, only the subgroup of respondents who experience high and average degree of mythological fears, in this case, possession by jinni.

Together with the survey, we conducted a psychological diagnosis of the entire survey sample to identify their individual psychological characteristics. Consequently, we got the expected results we have described in the previous section of this article.

To identify risks of negative religious influence, we carried out the comparative analysis of personal characteristics, which showed that, regardless of gender, logical correlation differences are found between subgroups experiencing high or medium level of mythological fears.

\section{CONCLUSIONS}

By analyzing the significant correlations in subgroups of young men and women a direct relationship is found between levels of degree of experiencing mythological fears and the availability of individual psychological dependency: cyclothymia and anxiety, emotionalality and anxiety; demonstrativeness and anxiety, externality and hyperthymia.

The diagnostic data obtained allowed us to develop a program of psychological and pedagogical support for students of educa-tional institutions, based on improving critical thinking and overcoming stereotypes of perception of reality, enhancing selfconfidence by forming adequate self-esteem, which includes 4 main modules: diagnostics; individual psychological counseling; training work; educational activities.

As well one of the necessary methods to prevent and control destructive transformations among the public in post-conflict areas, is the introduction into the curriculum of higher educational establishments in the Chechen Republic of discipline "Psychology of Religion."

\section{ACKNOWLEDGEMENTS}

The author would like to thank Professor I. V. Abakumova, Doctor of Psychology, under whose invaluable guidance this paper was written. She would also like to thank PhD. in Psychology AV. Miroshnichenko for his comments which led to substantial improvements in the paper.

\section{Conflict of interests}

Authors declare no conflict of interest.

\section{REFERENCES}

Grimsoltanova R. E, (2014a). Psychological features of mythological fears among representatives of Islam in adolescence, Rostov-on-Don, Retrieved from http://hub.sfedu.ru/media/diss/ e11202be-999c-4cc0-9687-7922da8989ce/\%D $0 \% 94 \% \mathrm{D} 0 \% \mathrm{~B} 8 \% \mathrm{D} 1 \% 81 \% \mathrm{D} 1 \% 81 \% \mathrm{D} 0 \% \mathrm{~B} 5 \%$ D1\%80\%D1\%82\%D0\%B0\%D1\%86\%D0\%B8 $\% \mathrm{D} 1 \% 8 \mathrm{~F} \% 20 \% \mathrm{D} 0 \% 93 \% \mathrm{D} 1 \% 80 \% \mathrm{D} 0 \% \mathrm{~B} 8 \% \mathrm{D}$ $0 \%$ BC $\%$ D $1 \% 81 \% \mathrm{D} 0 \% \mathrm{BE} \% \mathrm{D} 0 \% \mathrm{BB} \% \mathrm{D} 1 \% 82$ $\%$ D0 $\%$ B $0 \%$ D0 $\%$ BD $\%$ D0 $\%$ BE $\%$ D0 $\%$ B2\%D0 $\%$ BE $\%$ D0\%B9\%20\%D0\%A0.\%D0\%AD..pdf, pp. 173-174,

Grimsoltanova R. E, (2014b). Psychological features of mythological fears among representatives of Islam in adolescence, Rostov-on-Don, Retrieved from http://hub.sfedu.ru/media/diss/ e11202be-999c-4cc0-9687-7922da8989ce/\%D 0\%94\%D0\%B8\%D1\%81\%D1\%81\%D0\%B5\% D1\%80\%D1\%82\%D0\%B0\%D1\%86\%D0\%B8 $\% \mathrm{D} 1 \% 8 \mathrm{~F} \% 20 \% \mathrm{D} 0 \% 93 \% \mathrm{D} 1 \% 80 \% \mathrm{D} 0 \% \mathrm{~B} 8 \% \mathrm{D}$ $0 \%$ BC $\%$ D $1 \% 81 \% \mathrm{D} 0 \% \mathrm{BE} \% \mathrm{D} 0 \% \mathrm{BB} \% \mathrm{D} 1 \% 82$ $\% \mathrm{D} 0 \% \mathrm{~B} 0 \% \mathrm{D} 0 \% \mathrm{BD} \% \mathrm{D} 0 \% \mathrm{BE} \% \mathrm{D} 0 \% \mathrm{~B} 2 \% \mathrm{D} 0$ $\%$ BE $\%$ D0\%B9\%20\%D0\%A0.\%D0\%AD..pdf. pp. 176-192. 